\title{
Experimental study into compression after impact strength of laminates with conventional and nonconventional ply orientations
}

\author{
Yi Liv*, G. Guillamet, J. Costa, E.V. González, L. Marín, J.A. Mayugo \\ AMADE, Polytechnic School, University of Girona, Campus Montilivi s/n, 17071 Girona, Spain
}

\begin{abstract}
The quest for impact damage tolerant laminates by tailoring stacking sequences has led to nonconventional laminates whose ply sequences are not limited to $0, \pm 45$ and $90^{\circ}$. Departing from the hypothesis that compression after impact (CAI) strength is impaired by the presence of delaminations, a ply sequence was defined by selecting the mismatch angles between plies so as to maintain a central sublaminate with no, or small, delaminations. An experimental test campaign was devoted to validate this hypothesis. To that purpose, baseline and blocked-ply laminates were included in the study. Specimens were tested under low velocity impact followed by compression according to ASTM standards. Delaminations were identified with Ultrasonic C-Scan. The results show delamination locations being successfully predetermined by controlling the mismatch angle, as well as the ensuing improvement in compressive strength retention after impact.
\end{abstract}

Keywords: Nonconventional laminate, B. Delamination, B. Impact behaviour, B. Damage tolerance

\section{Introduction} life, and design flexibility for tailoring multidirectional properties to suit specific applications.

4 However, they exhibit poor damage resistance under Low Velocity Impact (LVI), and low

5 Compression After Impact (CAI) residual strength. Studies [1-4] show that LVI causes matrix cracks, 6 delamination and eventually fibre breakage for higher impact energies. Delamination is considered to be the most critical as it divide an impacted laminate into sublaminates, and consequently impairs

\footnotetext{
* Corresponding author: Yi Liv

Email address: yi.liv@udg.edu (Yi Liv )
} 
the post-impact load carrying capacity, as well as the stiffness and stability of the laminate. Under compression loading, impact-induced delaminations can propagate together with progressive sublaminate buckling, resulting in low CAI strength [5-8]. The reduction in the compressive strength due to impact damage can reach as high as $60 \%$ in a typical aerospace fibre-resin system [9].

In light of the low CAI strength, the quest for improved damage resistance and/or tolerant laminated composites in the context of the stacking sequence design has resulted in dispersed ply laminates [10-14]. A dispersed ply laminate has ply orientations not limited to the conventional $0, \pm 45$ and $90^{\circ}$ orientations, and hereafter is referred to as a nonconventional laminate. The stacking sequence design of the nonconventional laminates in $[13,14]$ exploited the idea that the mismatch angle (MMA) between the reinforcements of adjacent laminae has an effect on the tendency of that interface to delaminate. Small MMAs are less prone to delamination than large MMAs. The former tends to a blocked ply situation, whereas large MMA's cause severe shear stresses that promote delamination onset and growth, especially when the interface with large MMA is located close to the backface of the impacted laminate [11]. Following this rationale, Sebaey et al. [13, 14] compared nonconventional and baseline laminates with equivalent in-plane and bending stiffness and found that CAI strength of the nonconventional laminates was enhanced by up to $30 \%$ in comparison to that of a conventional layup. In previous studies, small and large values of MMA were dispersed through the thickness of the nonconventional laminates and it was suggested that the chance to improve CAI strength would be by controlling the through-the-thickness locations of delaminations [11]. Therefore, this paper depicts the first attempt to predetermine the location of delaminations generated in an LVI by selecting the MMA.

In the literature, MMA is not the only factor reported to affect the delamination size. Laminates with thick plies have been reported to influence delaminations areas, and other damage resistance parameters such as damage threshold loads and peak loads [15-17], but whether or not their CAI strength is in fact reduced remains unclear when the different experimental results reported in [16-18] are examined. Therefore, the effects of blocking plies (i.e. adjacent plies having $0^{\circ} \mathrm{MMA}$ ) on impact behaviour and CAI strength is revisited in this experimental campaign. This inclusion also allows the difference between ply thickness and mismatch angle to be observed.

Of interest in aerospace industry is the influence of moisture on the composite performance as it may alter the behaviour of the structure in different loading conditions. Ogi et al. [19] reported that 
moisture causes volumetric changes, reduces glass transition temperature $\left(T_{g}\right)$, and increases the critical stresses for transverse cracking and delamination by reducing residual stresses. Single-fibre fragmentation tests $[20,21]$ recently revealed that moisture is detrimental to the fibre/matrix interface shear strength. Regarding moisture effects on impact behaviour and CAI strength, experimental results are scarce. Moisture is reported to reduce the projected delamination area [22-24]. In [23], where only one impact energy level was studied, CAI strength was enhanced by the moisture effect. Therefore, this paper investigates whether moisture alters the observed trends of the effect of mismatch angles and ply thickness on LVI damage resistance and tolerance.

In summary, the objective of this work is to experimentally validate the hypothesis that the ply sequence of a nonconventional laminate can be tailored to predetermine the through-the-thickness location of delaminations created during a low velocity impact, and that the residual compressive strength (CAI) can be improved through this approach with respect to traditional quasi-isotropic laminates. Unconditioned and conditioned batches were analyzed. The results show that successfully locating the larger delaminations in the bottom sub-laminate was not accompanied by an improvement in CAI strength, but by a noticeable increase in strength retention after impact (especially in conditioned coupons).

\section{Rationale behind the selected layups}

\subsection{Baseline laminate (LBA)}

The stacking sequence of the baseline laminate LBA is $[90 /-45 / 0 / 45]_{3 s}$, which differs slightly from the layup recommended by the standard test ASTM D7136M-12 [25] ([45/0/-45/90]ns). The LBA ply sequence has $90^{\circ}$ ply on the laminate surface, a constant MMA value of $45^{\circ}$ between adjacent plies (except those at the laminate neutral plane) and no blocking of plies. Placing the $90^{\circ}$ ply as the outermost ply has been considered in some past studies and proven to be more impact resistant than having a $\pm 45^{\circ}$ ply on the surface [15], and to enhance buckling strains [26] and CAI strength [27].

\subsection{Nonconventional laminate (LNC)}

The aim to control the through-the-thickness location and size of the delaminations created in a low velocity impact by means of the mismatch angle between plies is the novelty of this study. As shown 
in Fig. 1, the NLC laminate is divided into three sublaminates: top, central and bottom. Our intention is to promote large delaminations at the bottom sublaminate and leave the central one mostly undamaged. This almost-pristine central sublaminate would account for an increase on the buckling strain as compared to a laminate where delaminations would be evenly distributed. This approach relies on previous findings that large MMA located close to the non-impacted face (specimen's bottom) results in large delaminations [11]. Therefore, large MMA values $\left(\geq 45^{\circ}\right)$ were imposed on all the interfaces within the bottom sublaminate. Large MMAs also appear within the top sublaminate due to the symmetry constraint. On the other hand, an MMA of $15^{\circ}$ was imposed on all the interfaces within the central sublaminate, because in previous studies interfaces with small MMAs $\left(10^{\circ}\right)$ had been found to result in no or undetectable delaminations when subjected to an ultrasonic C-Scan [13]. The aim of this approach is to dissipate the impact energy through large delaminations predetermined to appear at the bottom sublaminate. The rest of the laminate would be left with smaller delaminations thus, CAI strength is expected to be enhanced.

To avoid the differences in stiffness hiding the effect of the stacking sequence definition, both LNC and LBA were defined as having the same in-plane elastic properties. In addition to the aforementioned requirement, the following features of the LBA were regarded as constraints: same number of plies (24) and non-zero MMA (22), symmetry, balance, and quasi-isotropy. The LNC layup (Table 2) was obtained by means of the Ant Colony Optimization (ACO) algorithm [12]. Note that the number of $0^{\circ}$ plies is one-third that of the baseline.

[Figure 1 about here.]

\subsection{Thick-ply laminate (LTP)}

The stacking sequence of the thick-ply laminate is (Table 2), obtained by blocking plies of the same orientations. Note that ply thickness in this layup is three times that of the LBA, and a cluster of six $45^{\circ}$ plies is inevitable due to symmetry. Another important aspect is the reduction in the number of interfaces (potential sites for delamination) from 22 in the LBA to 6 in the LTP. 


\section{Experimental work}

\subsection{Material, specimen, and laminate properties}

Unidirectional prepreg tape with a nominal ply thickness of $0.184 \mathrm{~mm}$, supplied by $\mathrm{Hexcel}^{\circledR}$, was used to produce all the three laminates described in Section 2 according to standard autoclave procedures. The material is T800S/M21, a carbon/epoxy composite system of intermediate modulus, high tensile strength fibre preimpregnated in high-performance toughed matrix. The ply elastic properties of this composite system are summarized in Table 1. The full set of material properties along with their methods of characterization can be found in [28] and references therein.

\section{[Table 1 about here.]}

All the laminates were cut into 150 x $100 \mathrm{~mm}$ (length x width) test coupons. The $0^{\circ}$ ply direction of each layup is parallel to the length dimension of the test coupons.

The stacking sequence of each layup, as well as the MMA values, are presented in Table 2. Note that the three layups are quasi-isotropic, and all their in-plane elastic properties are constrained to be the same. Using the classical laminate theory and the ply elastic properties listed in Table 1 yields Young's modulus of 57.25 GPa, shear modulus of 21.68 GPa, and Poisson's ratio of 0.32. In the layup design, the equivalent bending stiffness $D^{*}$, an elastic parameter commonly used to assess the stiffness of an infinite composite plate under out-of-plane loading [29], was not constrained. However, its values for the three layups are reported here for completion. The $D^{*}$ values of the three layups along $0^{\circ}$, calculated according to [30], differ by less than $10 \%$ (Table 2 )

[Table 2 about here.]

[Figure 2 about here.]

\subsection{Test matrix}

The test matrix in this study is presented in Table 3, in which AR refers to "As Received" specimens and "WET" to specimens conditioned in a climatic chamber. Pristine/non-impacted coupons of each 
layup were also tested under compression for reference. Specimen conditioning and tests were conducted in the testing laboratory of the University of Girona, which is ISO 17025 and NADCAP (Non-metallic material testing laboratory) certified.

[Table 3 about here.]

\subsection{Experimental procedures}

Before impact tests, ultrasonic C-Scan (OLYMPUS OMNI MX) inspections to detect any premature damage caused during the cutting and handling of the specimens were carried out. Impact tests were performed according to ASTM D7136M-12 [25] with a CEAST Fractovis Plus drop-weight impact test machine. Contact load, time, velocity, displacement and absorbed energy evolution were automatically captured by the machine's instrumented software program. To assess impact-induced damage resistance, five parameters were considered: threshold load $F_{d}$, peak impact load $F_{\max }$, dissipated energy $E_{d i s}$, indentation depth $\delta_{i n d}$ and projected delamination area $A_{\text {pro }}$ (see, for instance, Fig. 3). $F_{d}$, on the load-time or load-displacement curves, is a sudden load drop or a decrease of slope due to specimen stiffness loss [31]. The displacement reported in this work is that of the impactor, not the mid-plane of the test coupon.

The indentation was measured within less than 5 minutes after the impact test, using a Mitutoyo dial depth gauge. For each impacted specimen, two indentation measurements at the impacted location were made: one by placing the gauge arms parallel to the specimen length and the other parallel to the specimen width. The indentation depth $\delta_{i n d}$ was taken as the average of the two measurements.

Each impacted specimen went through two C-Scan inspections: one for the impacted face and the other for non-impacted face. $A_{\text {pro }}$ was taken as the mean value of the projected delamination areas from the two C-Scan inspections. To obtain $A_{\text {pro }}$. Inkscape free software was used. Once the C-scan inspection were completed,

Compression tests of all impacted and non-impacted coupons were performed according to ASTM D7137M-12 [32] with an MTS 810 Servo-hydraulic Testing Machine equiped with a $250 \mathrm{kN}$ load cell at a loading rate of $1 \mathrm{~mm} / \mathrm{min}$. To ensure the proper loading alignment, a steel specimen bonded with four strain gauges was compressed up to the recommended load level where bending difference was found to be less than $10 \%$ [32]. 
Impact and CAI test configurations are described in [16]. This sequence of experimental tasks described here was used for both AR and WET specimens, and the difference in how we handled the WET specimens is explained in section 3.4.

\subsection{Conditioning and testing of WET specimens}

Three batches of each layup, referred to as WET in Table 3, were conditioned at $80^{\circ} \mathrm{C} / 85 \% \mathrm{RH}$ inside a CTS conditioning chamber until equilibrium state, following the prEN 2823 protocol [33]. After 2000 hours of conditioning, equilibrium state of approximately $1.26 \%$ weight gain was reached.

The sequence of tests from impact to CAI was the same as those described in section 3.3 with the only difference being in how we handled the WET specimens after each impact test prior to CAI. The total duration of an impact test and indentation measurement was less than 10 minutes, after which the specimen was returned to the chamber. Next, each specimen was subjected to the C-Scan inspection from impacted and non-impacted faces for less than 30 minutes and then put back into the chamber. This process was repeated for all the WET specimens to ensure that they lost about the same amount of moisture while they were outside the conditioning chamber. Before the specimens were compression tested, they were kept in the chamber for much more than two weeks so that they could regain the moisture content.

\section{Results}

\subsection{Impact test and $C$-Scan}

Impact responses of both AR and WET coupons at the explored impact energy levels are presented in Figs. 3 and 4. As the impact test reproducibility is reasonably good for both AR and WET coupons in terms of load-time history, only the mean value of load-displacement and impact energy evolution is shown (Fig.4) for ease of comparison. For AR coupons, the response of the baseline laminate (LBA) exhibits larger oscillations than those of the thick-ply (LTP) and nonconventional (LNC) laminates after $F_{d}$ is reached. Once $F_{d}$ is reached, separation between load-displacement curves emerges, at least for the AR coupons. On average, the $F_{d}$ of LTP and LNC is $30.5 \%$ and $3.5 \%$ lower than that of LBA $(5.50 \mathrm{kN})$. Note that the WET coupons of all the laminates have smoother 
responses than those of the AR coupons, making it hard to detect $F_{d}$ due to the absence of clear load drop as frequently reported in the literature.

[Figure 3 about here.]

[Figure 4 about here.]

Peak load $F_{\max }$ and dissipated energy $E_{d i s}$ are presented in Figs. 5 and 6 , respectively. As the impact energy increases, the mean values of both $F_{\max }$ and $E_{d i s}$ increase linearly. For both AR and WET conditions, LBA has the highest $F_{\max }$ and the lowest $E_{\text {dis }}$ on all impact energy levels, which is consistent with $F_{d}$ (LBA has the highest $F_{d}$ ). On average, the maximum absolute differences between the AR and WET coupons are $6.4 \%$ for $F_{\max }$ (of LTP at 20J), and $5.0 \%$ for $E_{d i s}$ (of LNC at 12J).

[Figure 5 about here.]

[Figure 6 about here.]

Like $F_{\max }$ and $E_{d i s}$, the indentation depth $\delta_{i n d}$ and projected delamination area $A_{\text {pro }}$ increase with increasing impact energy (see Figs. 7 and 8). The baseline laminate LBA experiences the lowest $\delta_{\text {ind }}$ and the smallest $A_{\text {pro }}$. Thick ply significantly affects both $\delta_{\text {ind }}$ and $A_{\text {pro }}$, particularly for the AR condition. Moisture consistently reduces the indentation depth $\delta_{\text {ind }}$ of all the laminates, and $A_{\text {pro }}$ for LTP and LNC only.

[Figure 7 about here.]

[Figure 8 about here.]

Presented in Fig. 9 is the C-Scan inspection revealing the shapes and sizes of the delaminated interfaces located through the thickness of the three laminates. Delaminations in LBA are more localized and circular than those seen in LTP and LNC. For the LTP AR specimens, delaminations are larger and more distinguishable, due to few non-zero MMA interfaces, than those of LBA and LNC. With the aid of the colour bar showing through-the-thickness locations of delaminated 
interfaces, the delamination sizes within the bottom sublaminate of LNC are seen to be larger than those within the central sublaminate. For the AR coupons of LTP and LNC tested at high energy, the extension of their delaminations reaches the window cut-out width $(75 \mathrm{~mm})$ of the impact fixture support. That is, the delamination area is highly constrained by the boundaries of the fixture.

[Figure 9 about here.]

\subsection{CAI test results}

Owing to a lack of impact energy levels, asymptotic behaviour of no damage (at lower impact energy levels) and perforation (at higher energy levels) does not appear on . Superior strengths are seen in LBA for AR specimens impacted at 12J and 20J, Fig. 10. For AR coupons, the compressive strength of non-impacted LTP and LNC is 10-19\% lower than that of LBA. The plot of normalized mean CAI strength in Fig. 10b reveals that the compressive strength retention of LTP and LNC at high impact energy (30J) is higher than that of LBA.

Moisture reduces the compressive strengths of pristine specimens in all the laminates. The strength of pristine WET coupons decreases compared to their AR counterparts by $7 \%, 14 \%$, and $12 \%$ on average for LBA, LTP, and LNC, respectively. For the impacted coupons at $12 \mathrm{~J}$ and $20 \mathrm{~J}$ there is a tendency to higher $\sigma_{C A I}$ for WET samples (except LTP at 12J and LBA at 20J). For WET impacted coupons, only for LNC does CAI strength increase monotonically in the presence of moisture with respect to $\mathrm{AR}$ conditions (17\% at $12 \mathrm{~J}$ and $16 \%$ at $20 \mathrm{~J}$, see Fig. 10a). Note that the LNC WET coupons have even higher $\sigma_{C A I}$ than those of LBA WET coupons at 20J.

[Figure 10 about here.]

\section{Discussion}

The first area to be discussed is whether the selection of the MMA's across the thickness of the LNC laminate (large MMA within the bottom sublaminate and small MMA within the central sublaminate, Fig. 1) allows the location of delaminations to be predetermined. C-scan analysis of the LNC laminate (Fig. 9) provides evidence of large delaminations within the bottom sublaminate and 
small delaminations within the central sublaminate, thus supporting the initial hypothesis of this work. The differences on the distribution of delamination sizes between LNC and LBA (the baseline) are clear. However, the approach did not result in completely preventing delaminations in the central sublaminate, as was the aim. The fact that the extension of delaminations at the bottom sublaminate was constrained by the boundaries should be taken into account. Considering that in impact events that do not produce fibre failure, delaminations are the main energy dissipating mechanism, the prospect is that an impact on a specimen larger than the one studied here, would have produced larger delaminations at the bottom sublaminate, at least for the impact energy levels equal to or greater than 20J. Larger delaminations mean more dissipated energy, so the extension of delaminations within the central sublaminate would be expected to decrease. That is, the success of the proposed approach (Fig. 1) avoiding delaminations in the central sublaminate is hindered by the effect of the boundaries.

Before addressing whether the compressive strength after impact improves in LNC, it should be made clear that comparing the compressive strength of LBA, LNC and LTP needs to be done with a certain amount of caution. Indeed, the failure under on-axis compression is a fibre-dominated mechanism which is very sensitive to the alignment of the reinforcement with the applied load $[34,35]$. LNC possesses three times fewer the number of $0^{\circ}$ plies found in the baseline LBA. This explains why LNC provided lower CAI strength than LBA did, albeit with the exception of specimens impacted at high energies (AR coupons impacted at 30J and WET coupons at 20J of Fig. 10). At these high impact energies the LNC retained their strength more efficiently than LBA and LTP. In terms of practical applications in aircraft structures, this behaviour is an asset.

The effect of blocking three plies (LTP laminate) is detrimental to both impact damage resistance and tolerance. In comparison to LBA, LTP results in lower $F_{d}$, lower $F_{\max }$, higher $E_{d i s}$, deeper $\delta_{i n d}$, larger $A_{\text {pro }}$, and low compressive strengths for both non-impacted and impacted specimens. The low damage resistance and tolerance of LTP can be attributed to the in-situ strength effect for matrix cracking (i.e. the strength decreases as the thickness of the ply increases) [36, 37]. Therefore, matrix cracking, and the associated delaminations, occurs earlier in blocked plies than in dispersed plies [4]. The effects of ply thickness on damage resistance to LVIs have also been reported in other studies $[13,15-18]$. Although the study conducted in this paper, and those in $[17,18]$, consider different composite systems and layups, the same effect of the blocking plies on CAI strength is observed. 
The impact behaviour of the three laminates is altered in the presence of moisture. Firstly, after $F_{d}$ is reached, load-time or load-displacement of the WET coupons exhibits smaller oscillations than those of the AR coupons; especially for LBA (Figs. 4). The physical reason behind this behaviour is unclear to the authors. Since delamination in the AR specimens tends to propagate unstably, this trend could be related to a tougher matrix (thus, interfaces) in WET specimens, as reported in [38]. The extension of delamination in Fig. 9 supports this idea for LTP and LNC in particular.

No sudden load drop due to specimen stiffness loss can be seen on either the load-time or load-displacement curves of the WET coupons (Figs. 3-4). Instead, the load-displacement curves show a gradual loss of stiffness about where the load is identified as $F_{d}$ in the figures mentioned above.

A tougher matrix could also explain the noticeable increase of the $F_{d}$ of LTP, compared to AR conditions as the onset of matrix cracking is delayed [23]. Reduced residual stresses associated to the plasticization of the matrix induced by moisture could also contribute to delaying the onset of damage mechanisms.

Moisture reduces the indentation depth $\delta_{\text {ind }}$ (Fig. 7). This same observation was reported elsewhere [24] but no explanation was given. Besides, moisture tends to reduce $A_{\text {pro }}$ of all the laminates, except the baseline LBA (Fig. 8). Reduced $A_{\text {pro }}$ in the presence of moisture was also reported in [22, 23]. Scanning electron microscopy (SEM) images in [23] reveal that the number of matrix transverse cracks and delamination sizes are smaller in the WET specimens than in the AR specimens. Again, this behaviour is coherent with a tougher matrix.

Lastly, while moisture does reduce the undamaged compressive strength, the effect on the compressive strength of impacted specimens depends on the laminate itself. CAI in LTP and LNC decreases for 12J but increases for $20 \mathrm{~J}$, where in LBA case, strength increases at $12 \mathrm{~J}$ and but not at $20 \mathrm{~J}$. Again, the retention for strength of LNC outperforms dramatically that of LBA.

An ongoing detailed microstructural investigation of damage evolution in quasistatic tests will contribute to clarifying the effect of moisture on the impact behaviour of these laminates. 


\section{Conclusion}

Three stacking sequences, LBA (quasi/isotropic baseline), LNC (nonconventional) and LTP (with blocked plies), were subjected to low velocity impact (LVI) and subsequently to compression after impact (CAI). LNC (with reinforcement orientations differing from conventional ones) was tailored to promote a central sublaminate being practically undamaged after LVI in order to achieve improved CAI strength. The LNC laminate was tailored by choosing small mismatch angles between plies at the central sublaminate, whereas at the upper and bottom sublaminates they were equal or larger than $45^{\circ}$. Specimens from the three layups were studied under two conditions: as-received (AR) and conditioned (WET, $\left.80^{\circ} \mathrm{C} / 85 \% \mathrm{RH}\right)$.

C-Scan inspection proved that, by selecting mismatch angle between plies, it is feasible to predetermine the location of delaminations through the thickness of LNC. While this did not result in an improvement of CAI strength in LNC, it did result in an increase in strength retention after impact (more noticeably in WET conditions). In fact, the compressive strength can not be compared directly because LNC possesses one third of the $0^{\circ}$ plies that LBA has, consequently lowering its effective load-carrying capacity under compression.

Blocking three plies impaired the impact resistance as well as the compressive strength of pristine and impacted specimens.

While moisture tends to improve damage resistance and tolerance to LVI with respect to the AR counterparts, its effect is far greater on LTP laminate (an increase in the $F_{d}$ and reduction in the projected delamination area). Under compression loading, moisture decreases the compressive strength of the non-impacted coupons, but the influence on the impacted coupons is diverse. The influence of moisture on LVI behaviour and the associated damage pattern deserves further investigation. 


\section{Acknowledgment}

The first author would like to thank the Generalitat de Catalunya for the FI-DGR pre-doctoral grant (2015FI-B1 00144). The authors acknowledge the financial support of the Spanish Ministerio de Ciencia e Innovación under the project MAT2012-37552-C03-03 which is partially funded by the FEDER program.

\section{References}

[1] Geubelle PH, Baylor JS. Impact-induced delamination of composites: a 2D simulation. Composites Part B: Engineering 1998;29(5):589 - 602.

[2] de Freitas M, Silva A, Reis L. Numerical evaluation of failure mechanisms on composite specimens subjected to impact loading. Composites Part B: Engineering 2000;31(3):199 - 207.

[3] Bull DJ, Spearing SM, Sinclair I. Investigation of the response to low velocity impact and quasi-static indentation loading of particle-toughened carbon-fibre composite materials. Composites Part A: Applied Science and Manufacturing 2015;74(0):38-46.

[4] Wagih A, Maimí P, Blanco N, Costa J. A quasi-static indentation test to elucidate the sequence of damage events in low velocity impacts on composite laminates. Composites Part A: Applied Science and Manufacturing 2016;82:180 -9.

[5] Guédra-Degeorges D. Recent advances to assess mono- and multi-delaminations behaviour of aerospace composites. Composites Science and Technology 2006;66(6):796-806. Advances in statics and dynamics of delamination Workshop on Advances in Modeling Delamination in Composite Materials and Structures.

[6] Suemasu H, Sasaki W, Ishikawa T, Aoki Y. A numerical study on compressive behavior of composite plates with multiple circular delaminations considering delamination propagation. Composites Science and Technology 2008;68(12):2562 -7. Deformation and Fracture of Composites: Analytical, Numerical and Experimental Techniques, with regular papers.

[7] Rivallant S, Bouvet C, Hongkarnjanakul N. Failure analysis of CFRP laminates subjected to compression after impact: FE simulation using discrete interface elements. Composites Part A: Applied Science and Manufacturing 2013;55:83 - 93. 
[8] Bull DJ, Spearing SM, Sinclair I. Observations of damage development from compression-after-impact experiments using ex situ micro-focus computed tomography. Composites Science and Technology 2014;97:106 -14.

[9] Hawyes VJ, Curtis PT, Soutis C. Effect of impact damage on the compressive response of composite laminates. Composites Part A: Applied Science and Manufacturing 2001;32(9):1263-70.

[10] Rahul, Chakraborty D, Dutta A. Optimization of FRP composites against impact induced failure using island model parallel genetic algorithm. Composites Science and Technology 2005;65(13):2003 -13.

[11] Lopes CS, Seresta O, Coquet Y, Gürdal Z, Camanho PP, Thuis B. Low-velocity impact damage on dispersed stacking sequence laminates. Part I: Experiments. Composites Science and Technology 2009;69(78):926-36.

[12] Sebaey TA, González EV, Lopes CS, Blanco N, Costa J. Damage resistance and damage tolerance of dispersed CFRP laminates: Design and optimization. Composite Structures 2013;95(0):569-76.

[13] Sebaey TA, González EV, Lopes CS, Blanco N, Costa J. Damage resistance and damage tolerance of dispersed CFRP laminates: Effect of ply clustering. Composite Structures 2013;106(0):96-103.

[14] Sebaey TA, González EV, Lopes CS, Blanco N, Maimí P, Costa J. Damage resistance and damage tolerance of dispersed CFRP laminates: Effect of the mismatch angle between plies. Composite Structures 2013;101(0):255-64.

[15] Fuoss E, Straznicky PV, Poon C. Effects of stacking sequence on the impact resistance in composite laminates-Part 1: parametric study. Composite Structures 1998;41(1):67 - 77.

[16] González EV, Maimí P, Camanho PP, Lopes CS, Blanco N. Effects of ply clustering in laminated composite plates under low-velocity impact loading. Composites Science and Technology 2011;71(6):805-17.

[17] Rueda SH. Curing, defects and mechanical performance of fiber-reinforced composites. Ph.D. thesis; Universidad Politécnica de Madrid; 2013. 
[18] Dost EF, Ilcewicz LB, Avery WB, Coxon BR. Effects of Stacking Sequence on Impact Damage Resistance and Residual Strength for Quasi-Isotropic Laminates. In: O'Brien T K, editor. Composite materials: Fatigue and fracture. Vol. 3 (A92-39001 16-39). Philadelphia, PA, American Society for Testing and Materials: ASTM; 1991, p. 476-500.

[19] Ogi K, Kim HS, Maruyama T, Takao Y. The influence of hygrothermal conditions on the damage processes in quasi-isotropic carbon/epoxy laminates. Composites Science and Technology 1999;59(16):2375 -82.

[20] Cauich-Cupul JI, Pérez-Pacheco E, Valadez-González A, Herrera-Franco PJ. Effect of moisture absorption on the micromechanical behavior of carbon fiber/epoxy matrix composites. Journal of Materials Science 2011;46(20).

[21] Pérez-Pacheco E, Cauich-Cupul JI, Valadez-González A, Herrera-Franco PJ. Effect of moisture absorption on the mechanical behavior of carbon fiber/epoxy matrix composites. Journal of Materials Science 2013;48(5):1873-82.

[22] Imielińska K, Guillaumat L. The effect of water immersion ageing on low-velocity impact behaviour of woven aramidglass fibre/epoxy composites. Composites Science and Technology 2004;64(1314):2271 -8.

[23] Aoki Y, Yamada K, Ishikawa T. Effect of hygrothermal condition on compression after impact strength of CFRP laminates. Composites Science and Technology 2008;68(6):1376-83.

[24] Zhong Y, Joshi SC. Impact behavior and damage characteristics of hygrothermally conditioned carbon epoxy composite laminates. Materials and Design 2015;65:254 -64.

[25] ASTM D7136 / D7136M-12. Standard Test Method for Measuring the Damage Resistance of a Fiber-Reinforced Polymer Matrix Composite to a Drop-Weight Impact Event. 2012.

[26] Rhead AT, Butler R. Compressive static strength model for impact damaged laminates. Composites Science and Technology 2009;69(14):2301-7. The Sixteenth International Conference on Composite Materials with Regular Papers.

[27] Rhead AT, Butler R, Baker N. Analysis and Compression Testing of Laminates Optimised for Damage Tolerance. Applied Composite Materials 2011;18(1):85-100. 
[28] Marín L, González E, Maimí P, Trias D, Camanho P. Hygrothermal effects on the translaminar fracture toughness of cross-ply carbon/epoxy laminates: Failure mechanisms. Composites Science and Technology 2016;122:130 -9.

[29] Sebaey TA, González EV, Lopes CS, Blanco N, Costa J. Damage resistance and damage tolerance of dispersed CFRP laminates: The bending stiffness effect. Composite Structures 2013;106(0):30-2.

[30] Olsson R. Analytical prediction of large mass impact damage in composite laminates. Composites Part A: Applied Science and Manufacturing 2001;32(9):1207-15.

[31] Schoeppner GA, Abrate S. Delamination threshold loads for low velocity impact on composite laminates. Composites Part A: Applied Science and Manufacturing 2000;31(9):903-15.

[32] ASTM D7136 / D7137M-12. Standard Test Method for Compressive Residual Strength Properties of Damaged Polymer Matrix Composite Plates. 2012.

[33] prEN-2823. Aerospace series-Fibre reinforced plastics-determination of the effect of exposure to humid atmosphere on physical and mechanical characteristics. 1998.

[34] Berbinau P, Soutis C, Goutas P, Curtis PT. Effect of off-axis ply orientation on $0^{\circ}$-fibre microbuckling. Composites Part A: Applied Science and Manufacturing 1999;30(10):1197 -207.

[35] Ataabadi AK, Hosseini-Toudeshky H, Rad SZ. Experimental and analytical study on fiber-kinking failure mode of laminated composites. Composites Part B: Engineering 2014;61:84 $-93$.

[36] Camanho PP, Dávila CG, Pinho ST, Iannucci L, Robinson P. Prediction of in situ strengths and matrix cracking in composites under transverse tension and in-plane shear. Composites Part A: Applied Science and Manufacturing 2006;37(2):165-76. CompTest 2004.

[37] Sebaey TA, Costa J, Maimí P, Batista Y, Blanco N, Mayugo JA. Measurement of the in situ transverse tensile strength of composite plies by means of the real time monitoring of microcracking. Composites Part B: Engineering 2014;65(0):40-6. Damage Mechanics.

[38] Hintikka P, Wallin M, Saarela O. The effect of moisture on the interlaminar fracture toughness of CFRP laminate. In: 27th International Congress of the Aeronautical Sciences. Nice, France. 19-24 September. 2010, p. 1-8. 


\section{Impactor}

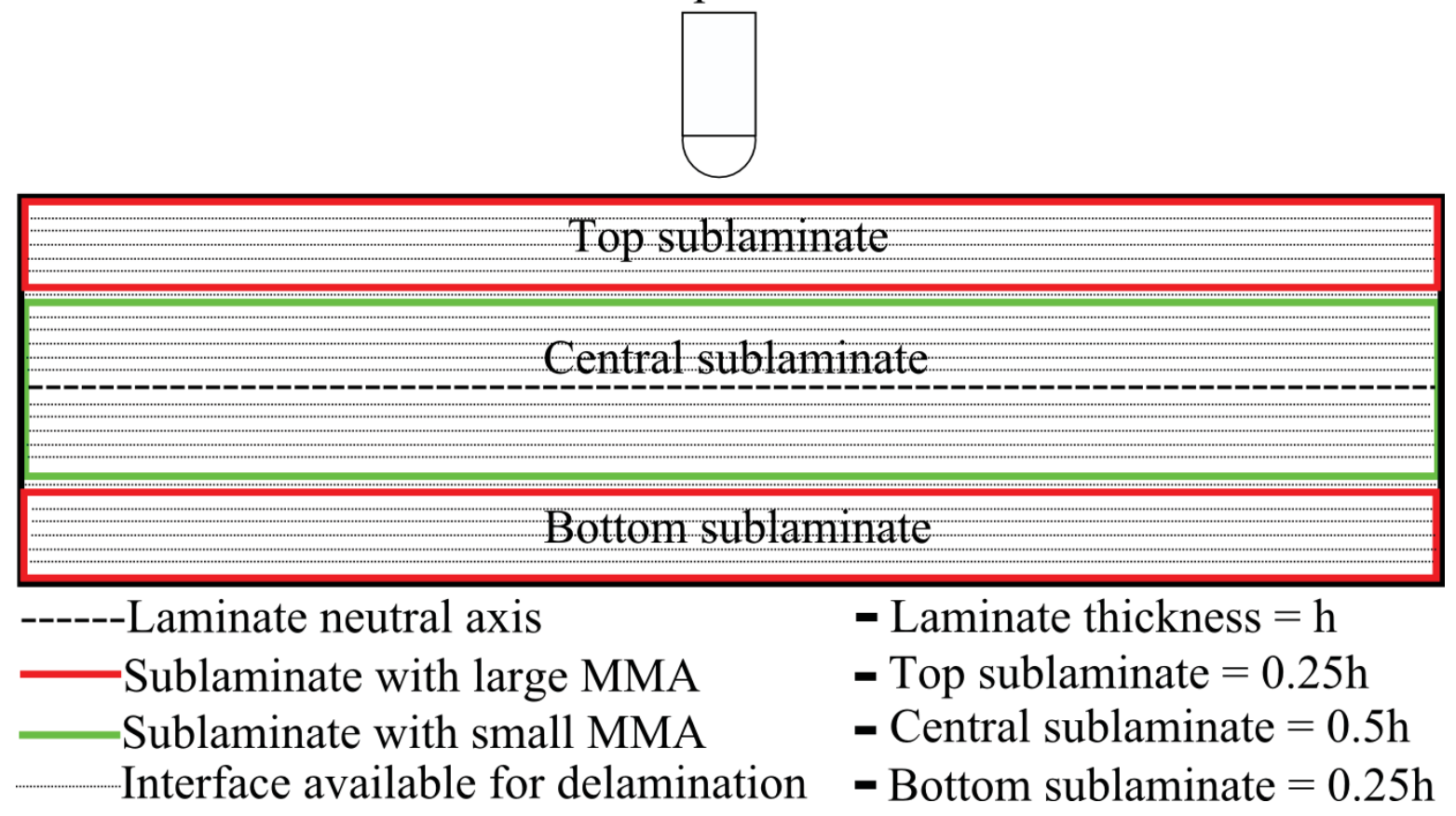

Figure 1: Through-the-thickness view illustrating definition of the tailored nonconventional laminate (LNC) comprising of three sublaminates: top and bottom sublaminates with large MMAs of $45-60^{\circ}$ and central sublaminate with small MMAs of $15^{\circ}$. (For interpretation of the references to colour in this figure legend, the reader is referred to the web version of this article.)

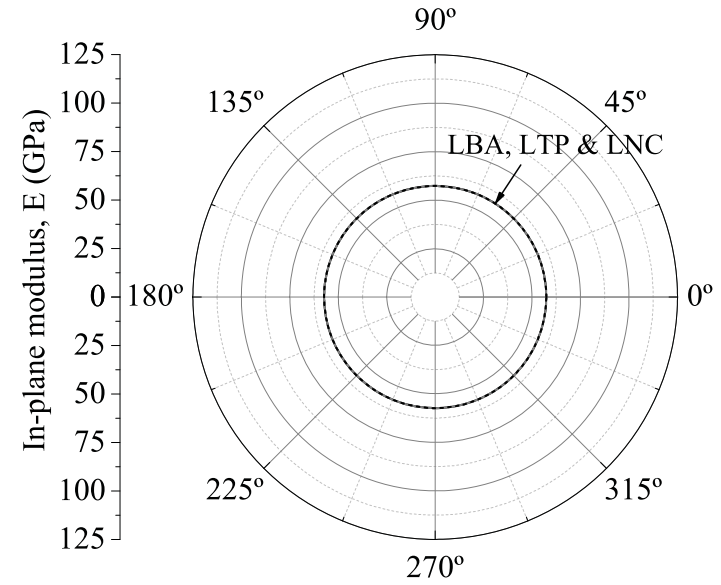

(a)

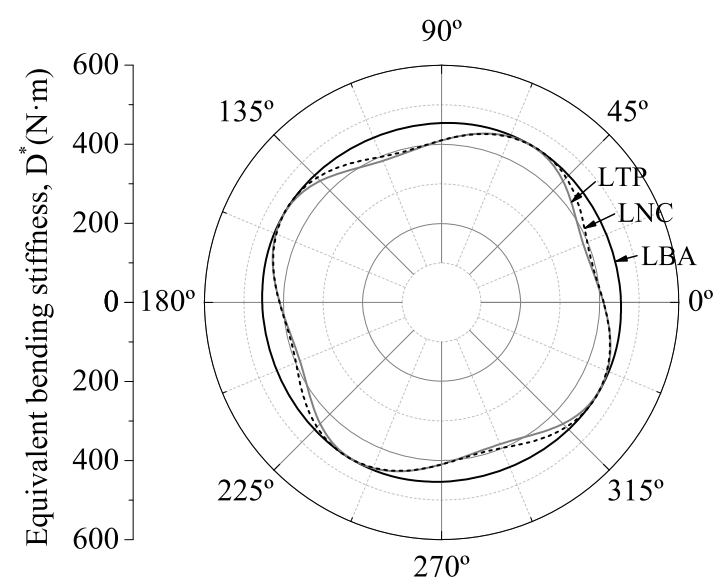

(b)

Figure 2: Young's modulus (a) and equivalent bending stiffness (b). LBA: Baseline, LNC: Nonconventional, and LTP: Thick-ply. 


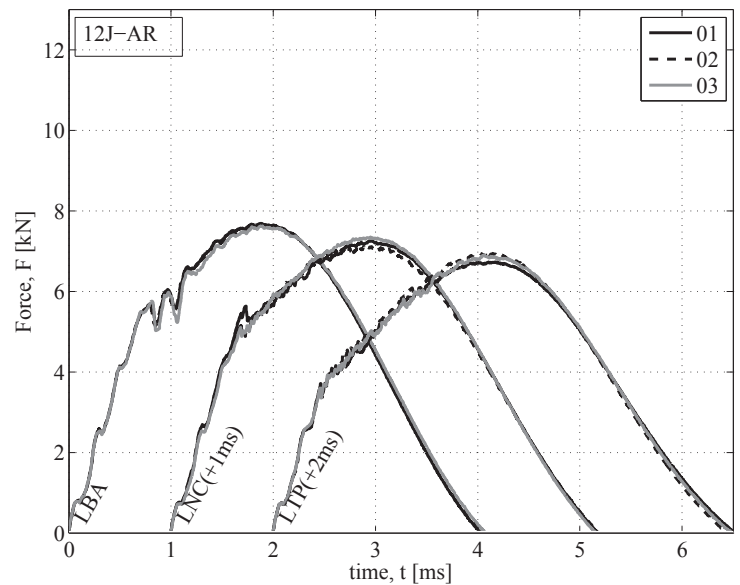

(a)

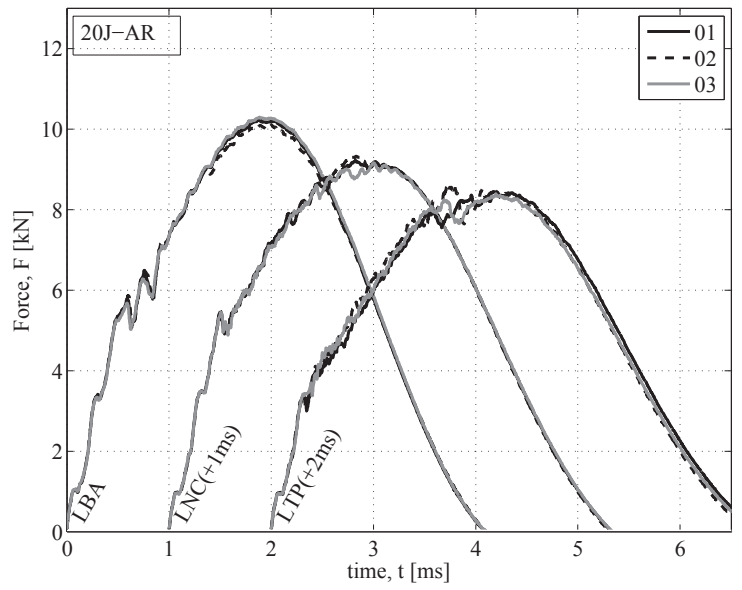

(c)

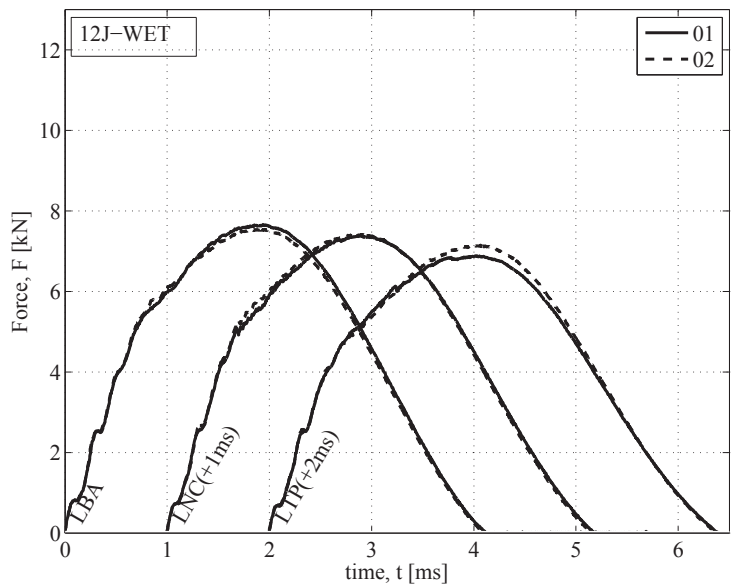

(b)

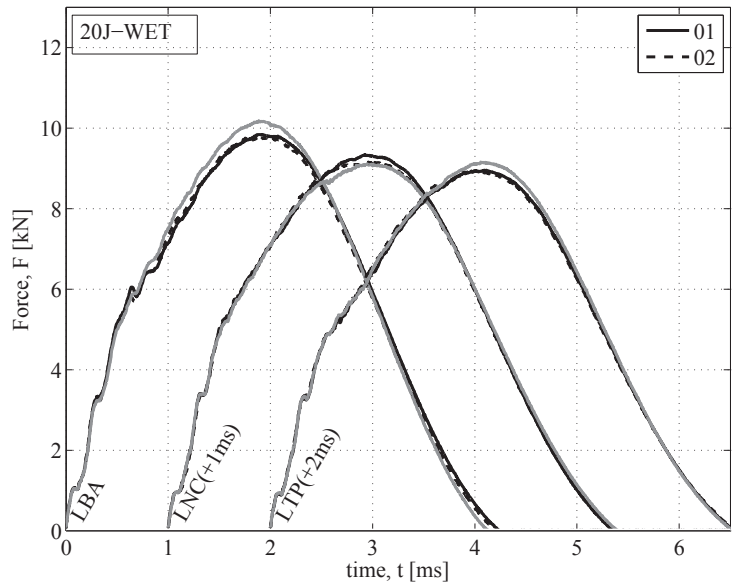

(d)

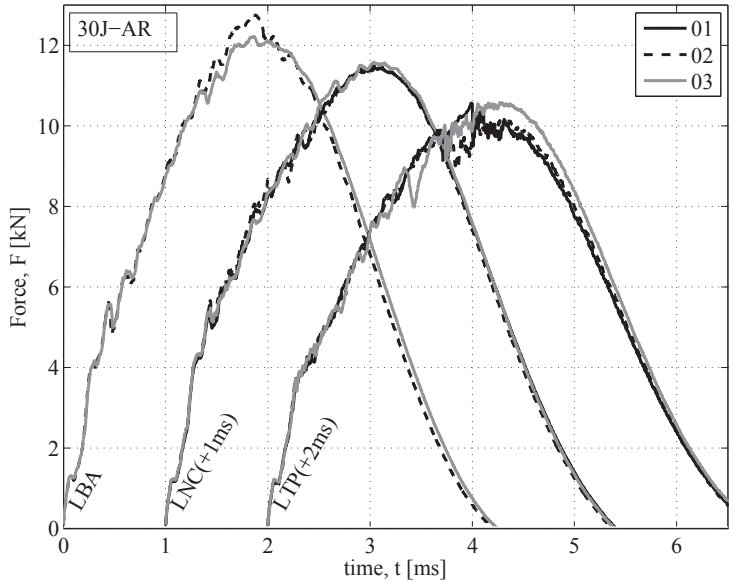

(e)

Figure 3: Load-time response at different impact energy levels. LBA: Baseline, LNC: Nonconventional, and LTP: Thick-ply. Responses of LNC and LTP are offset by 1 and $2 \mathrm{~ms}$ respectively for ease of comparison. 


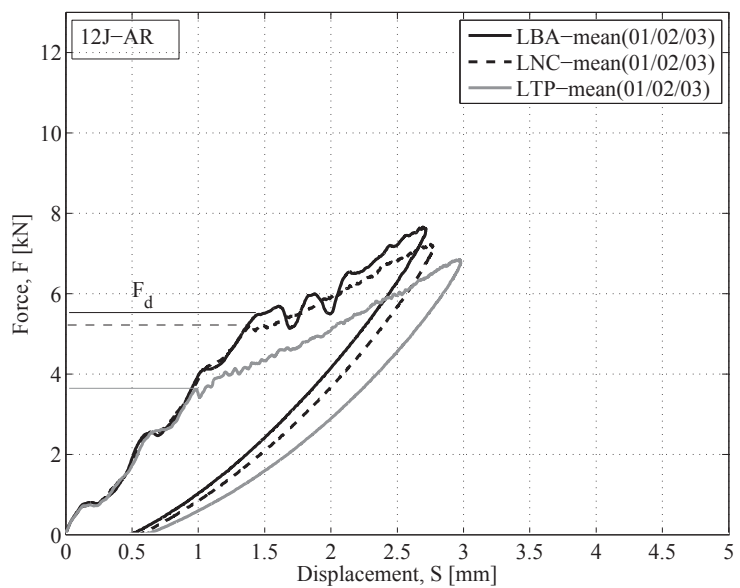

(a)

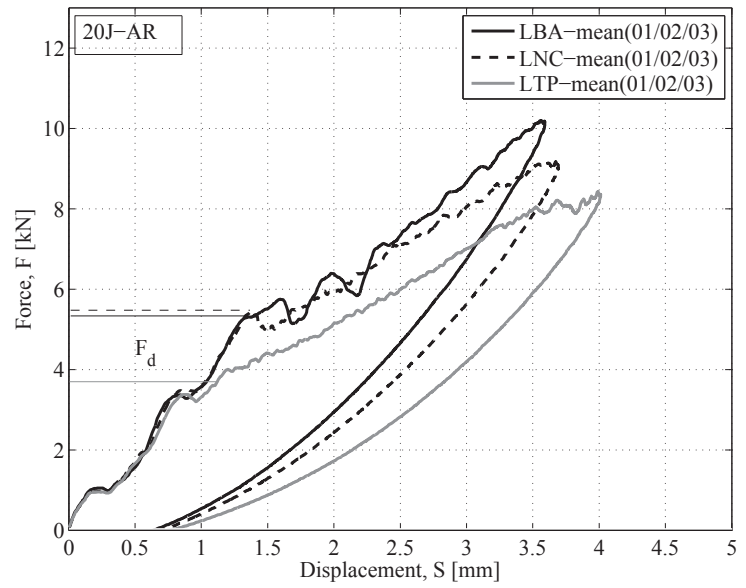

(c)

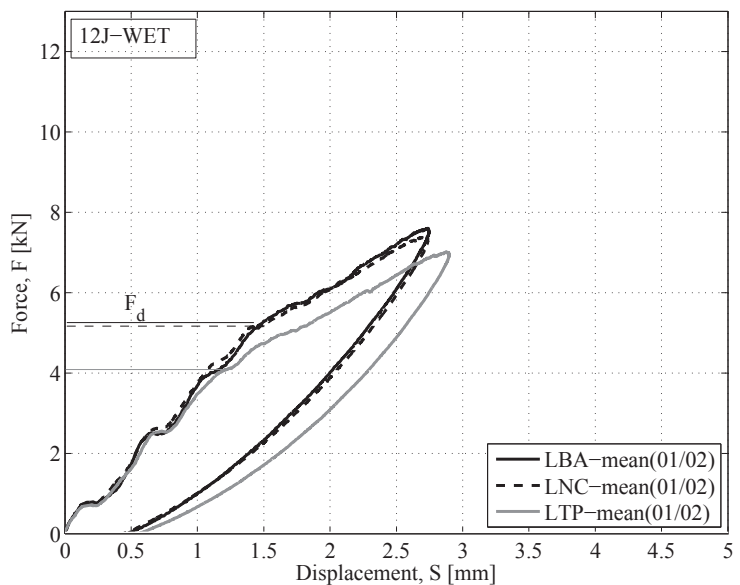

(b)

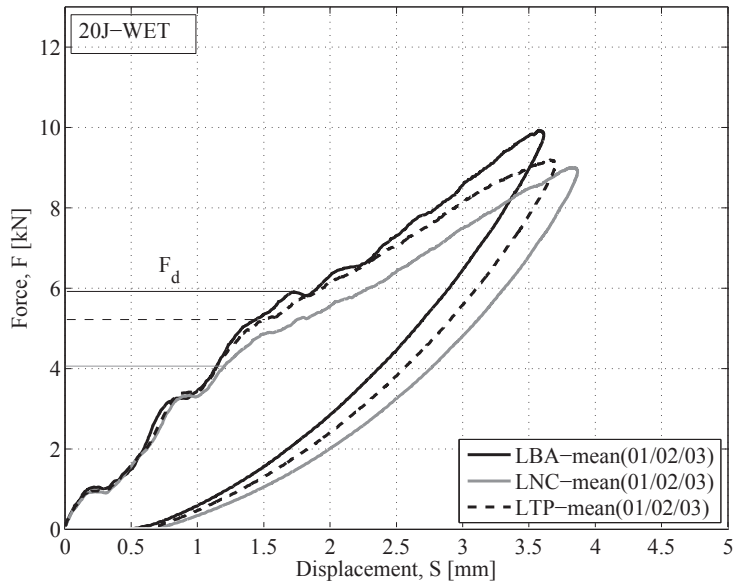

(d)

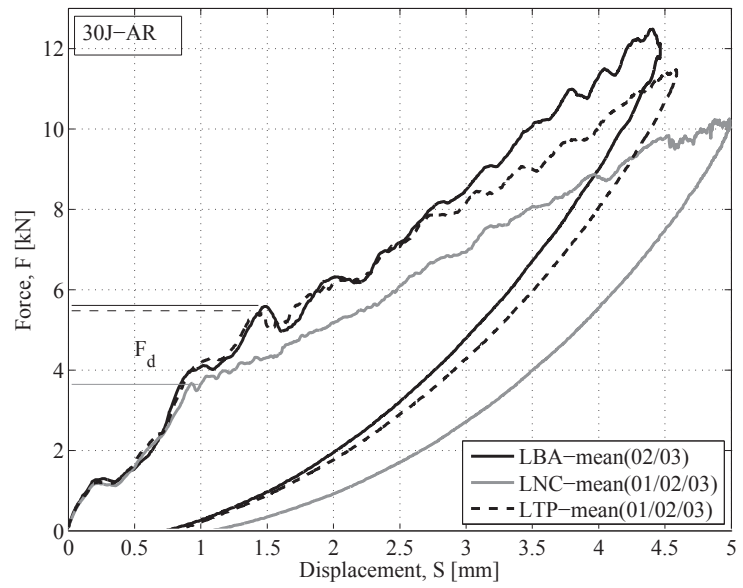

(e)

Figure 4: Load-displacement mean response at different impact energy levels. LBA: Baseline, LNC: Nonconventional, and LTP: Thick-ply. 


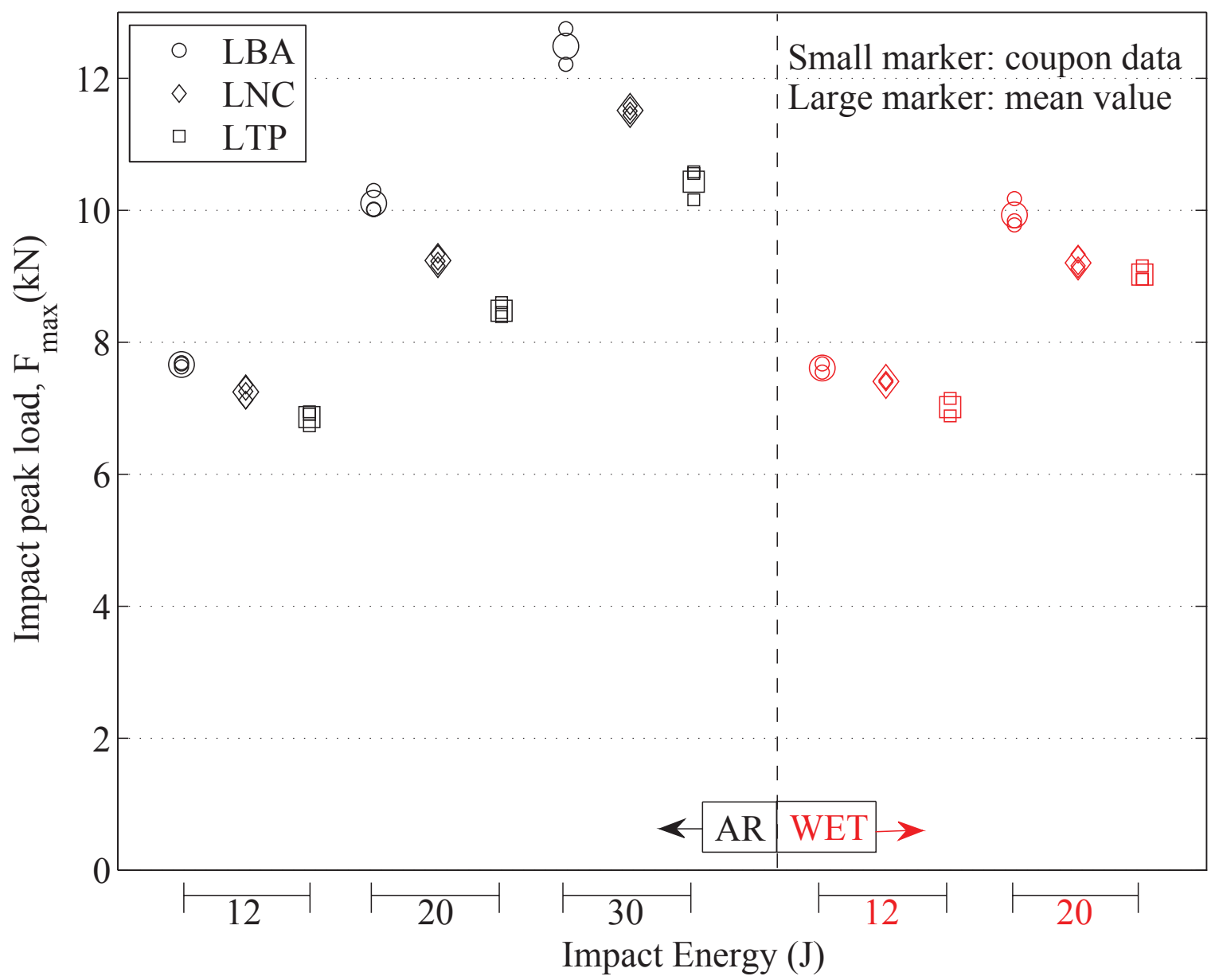

Figure 5: Impact peak load; LBA: Baseline, LNC: Nonconventional, and LTP: Thick-ply. No WET coupons were tested at $30 \mathrm{~J}$. (For interpretation of the references to colour in this figure legend, the reader is referred to the web version of this article.) 


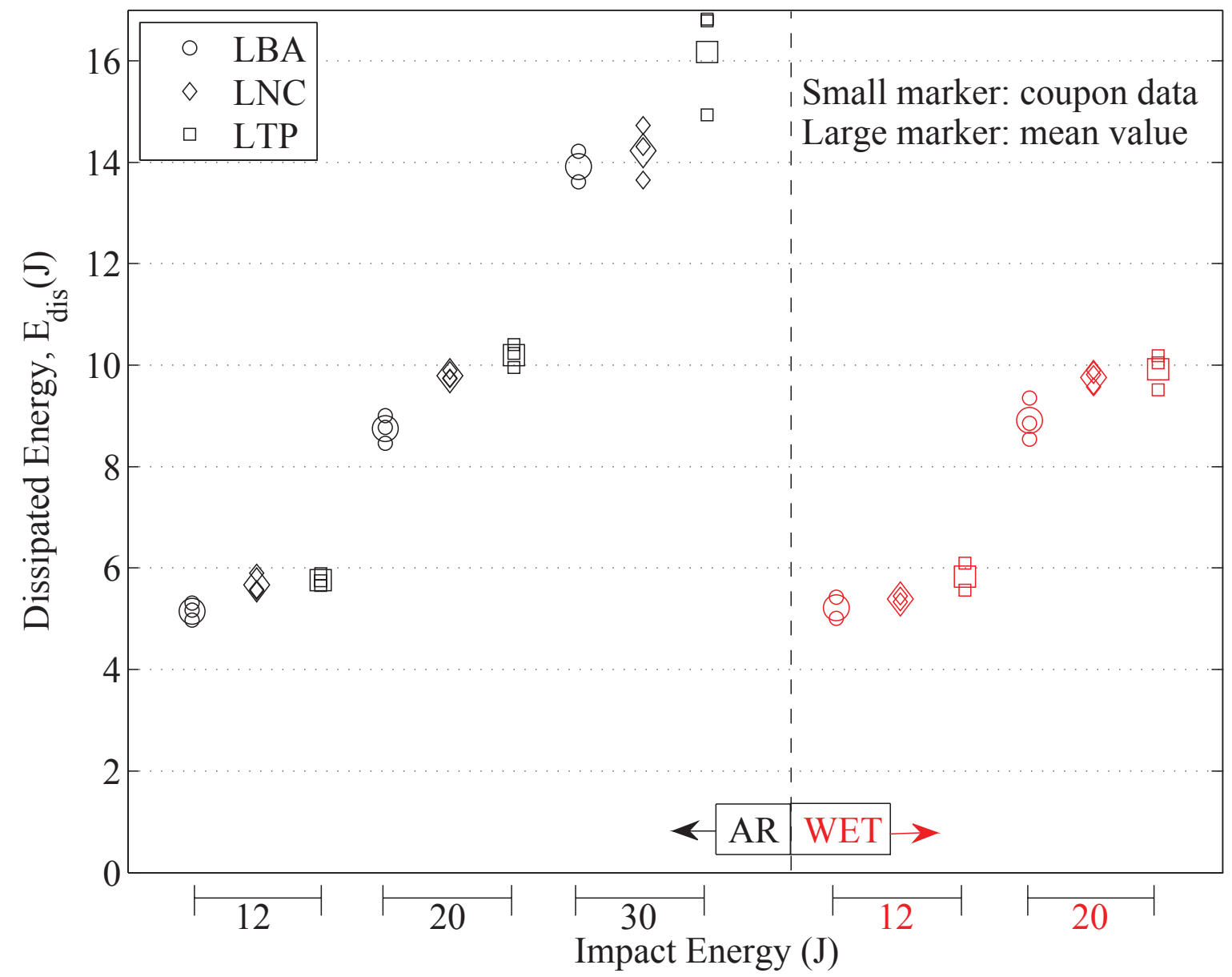

Figure 6: Dissipated energy; LBA: Baseline, LNC: Nonconventional, and LTP: Thick-ply. No WET coupons were tested at 30J. (For interpretation of the references to colour in this figure legend, the reader is referred to the web version of this article.) 


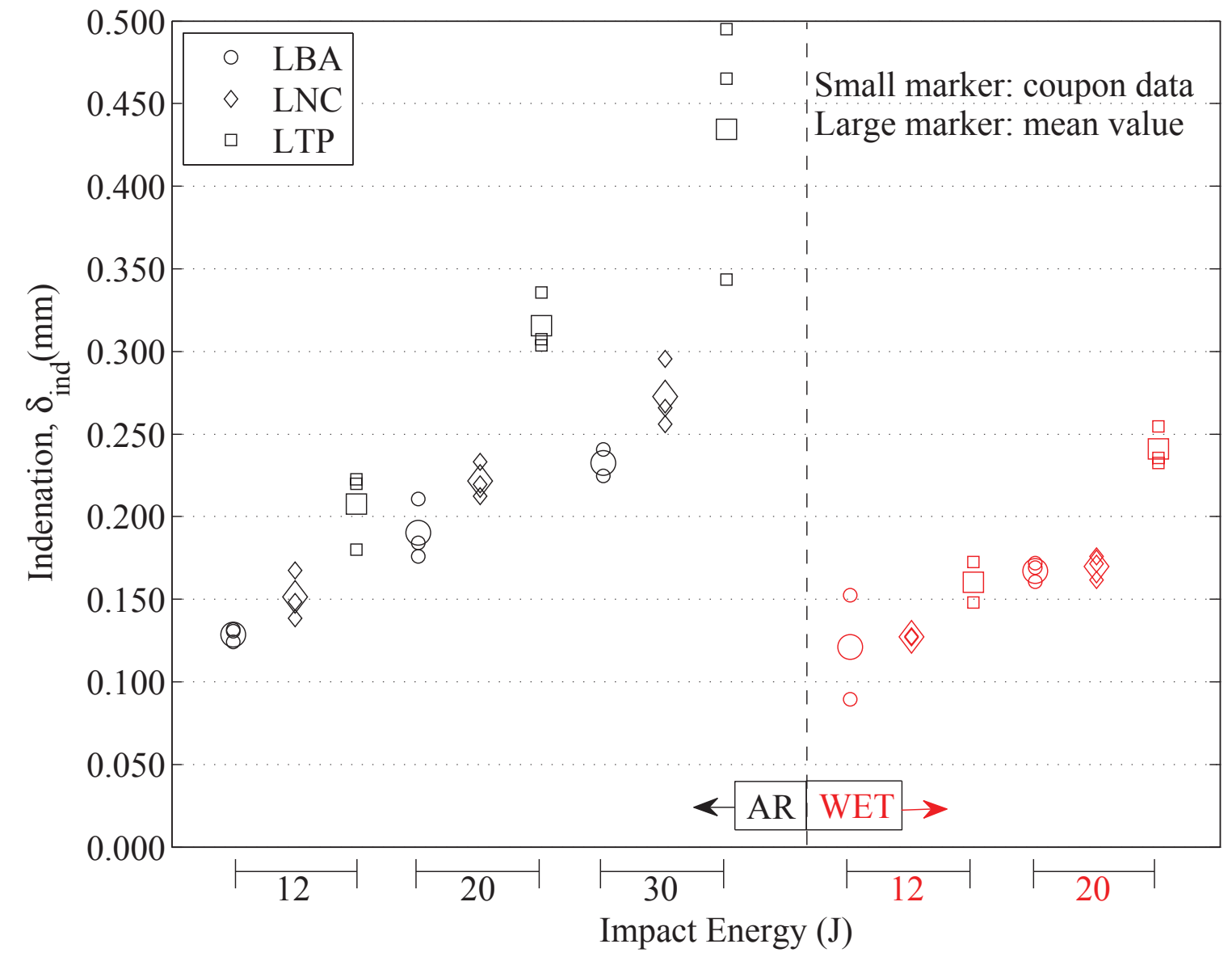

Figure 7: Indentation depth; LBA: Baseline, LNC: Nonconventional, and LTP: Thick-ply. For each individual specimen, indentation depth was taken as mean value of those depths measured by placing the gauge arms along the specimen length and width; no WET coupons were tested at 30J. (For interpretation of the references to colour in this figure legend, the reader is referred to the web version of this article.) 


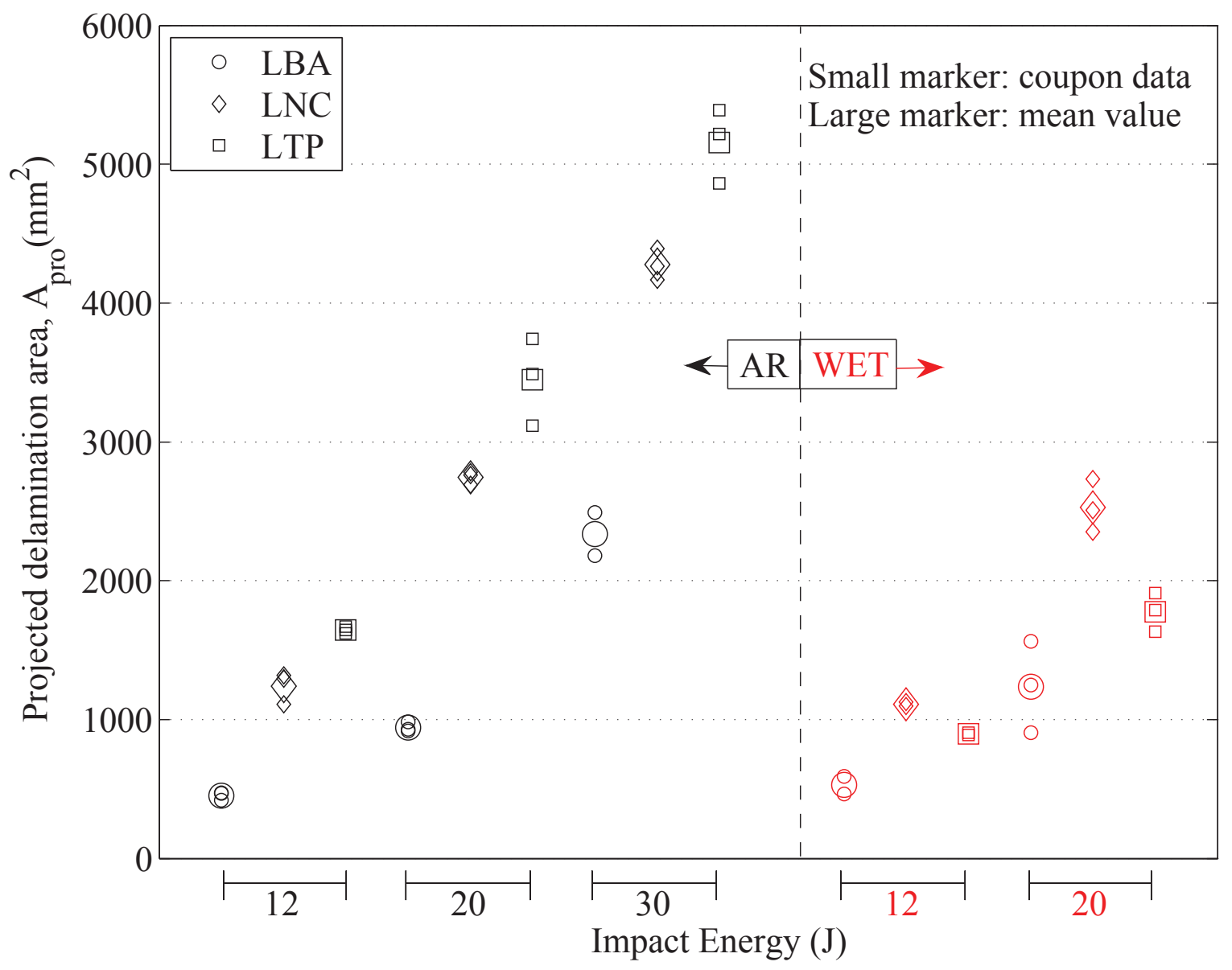

Figure 8: Projected delamination area; LBA: Baseline, LNC: Nonconventional, and LTP: Thick-ply. For each individual specimen, projected delamination was taken as mean value of those projected delamination areas observed through C-Scan from impacted and non-impacted faces; no WET coupons were tested at 30J. 


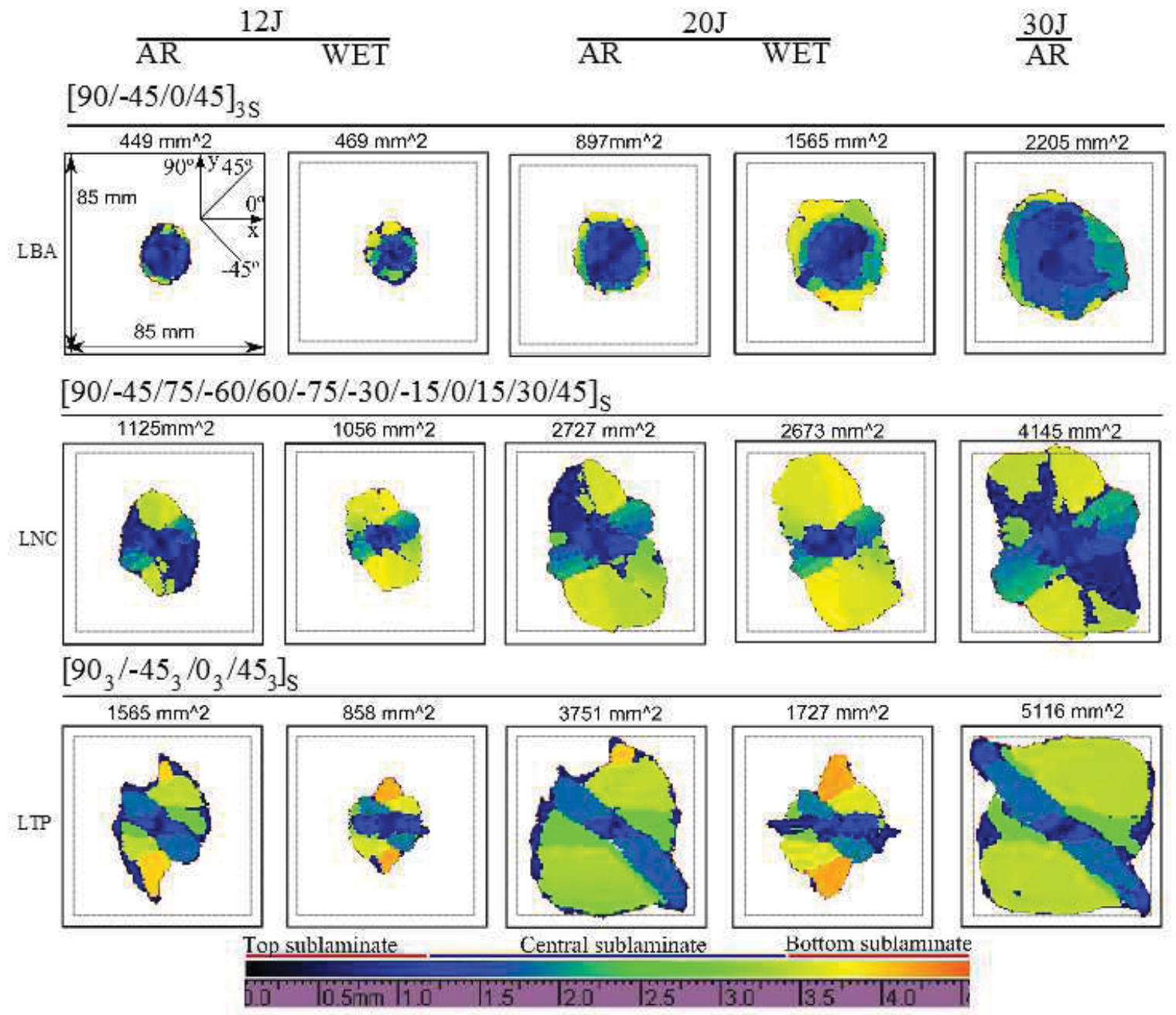

Figure 9: C-Scan inspection of delaminated interfaces; LBA: Baseline, LNC: Nonconventional, and LTP: Thick-ply. Colour bar indicates the depth of coupon as measured from the non-impacted face. No WET coupons were tested at $30 \mathrm{~J} ; 75 \mathrm{~mm}$ is the shortest in-plane dimension of the window cut $(125 \times 75 \mathrm{~mm})$ on impact fixture as specified in ASTM D7136M-12 [25]. (For interpretation of the references to colour in this figure legend, the reader is referred to the web version of this article.) 


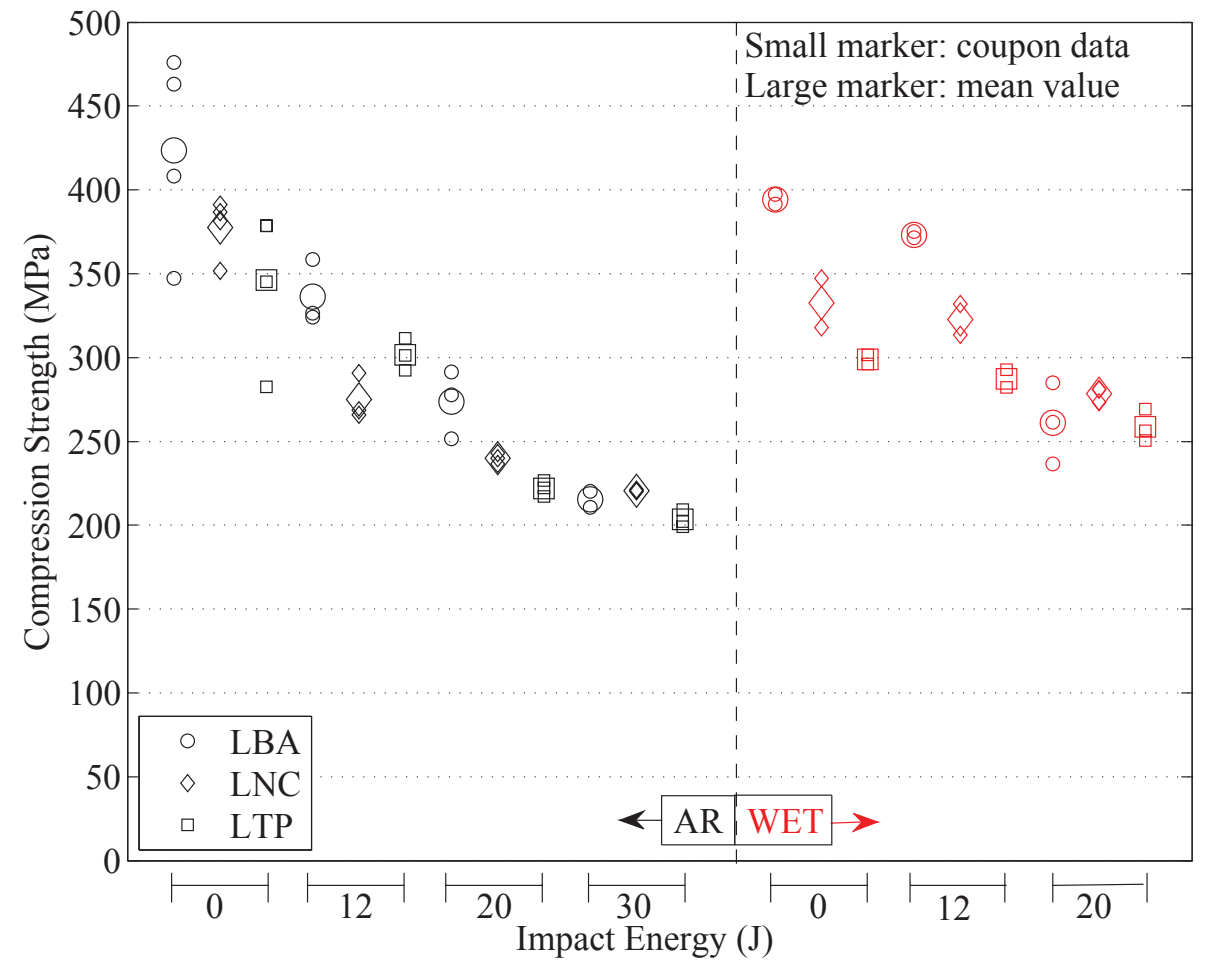

(a)

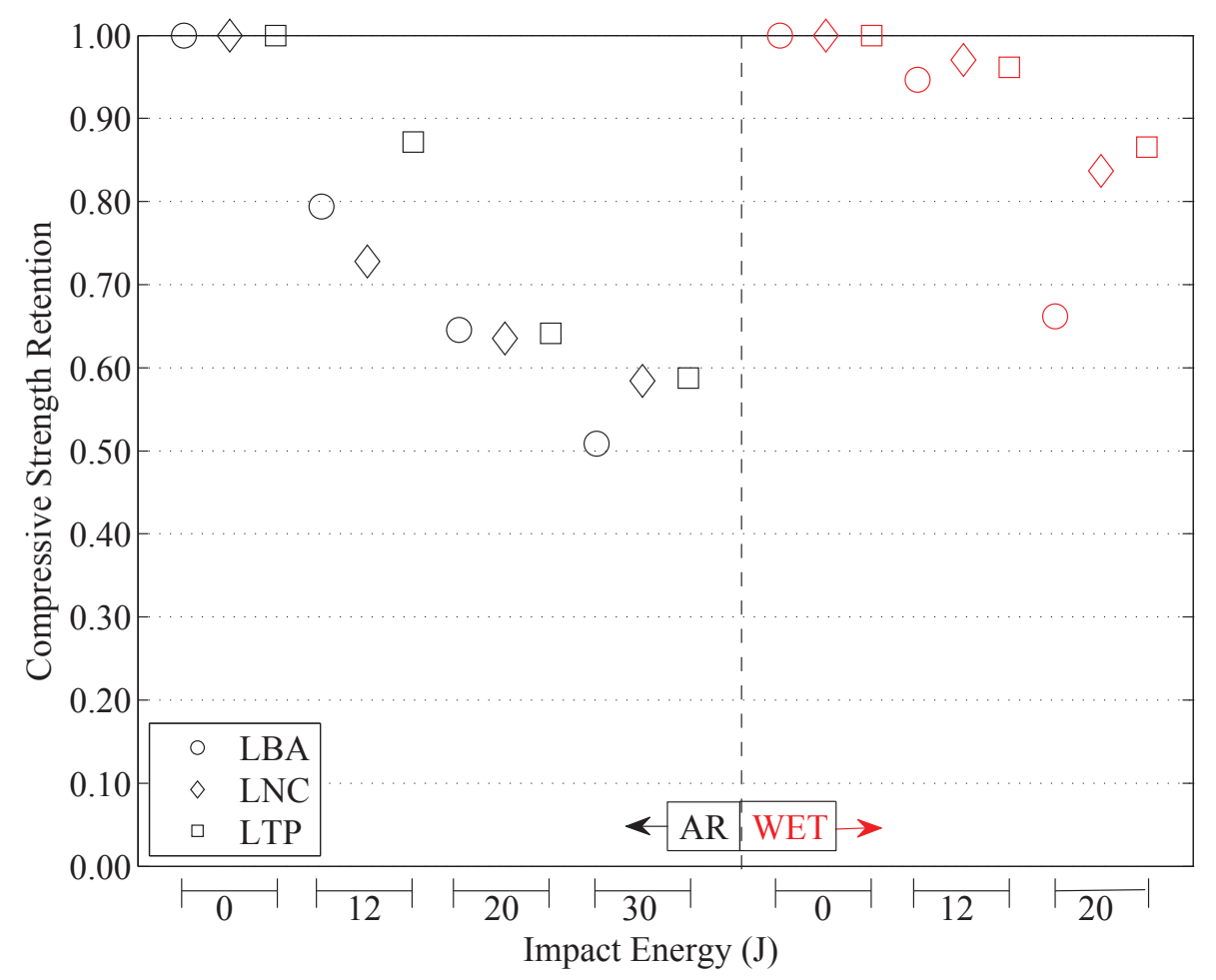

(b)

Figure 10: Compression and CAI strength (a), and mean compression retention strength (b); LBA: Baseline, LNC: Nonconventional, and LTP: Thick-ply. 0J: non-impacted/pristine coupons; no WET coupons were tested at 30J. (For interpretation of the references to colour in this figure legend, the reader is referred to the web version of this article.) 
Table 1: Elastic properties of T800S/M21 unidirectional ply [28]

\begin{tabular}{llll}
\hline Property & Unit & Value & Description \\
\hline$E_{11}$ & GPa & 152.8 & Longitudinal Young's modulus \\
$E_{22}=E_{33}$ & GPa & 8.7 & Transverse Young's moduli \\
$\nu_{12}=\nu_{13}$ & - & 0.335 & Poisson ratio in planes 1-2 and 1-3 \\
$\nu_{23}$ & - & 0.380 & Poisson ratio in plane 2-3 \\
$G_{12}$ & GPa & 4.2 & Shear moduli in planes 1-2 and 2-3 \\
$G_{23}$ & GPa & 3.15 & Shear modulus in plane and 2-3 \\
\hline
\end{tabular}

415

Table 2: Stacking sequences and mismatch angle (MMA) of two adjacent plies; ply count: total number of plies; int count: total number of interfaces with non-zero MMA; ply thickness: $0.184 \mathrm{~mm}$; *: interface at the midplane. Equivalent bending stiffness $\left(D^{*}\right)$ values presented here are along $0^{\circ}$.

\begin{tabular}{|c|c|c|c|c|c|c|c|c|c|c|c|c|c|c|}
\hline \multicolumn{15}{|c|}{ Laminate labels and stacking sequences } \\
\hline Laminate & Decription & Ply/Int count & \multicolumn{8}{|c|}{ Stacking sequences } & \multicolumn{4}{|c|}{$D^{*}(\mathrm{Nm})$} \\
\hline$\overline{\mathrm{LBA}}$ & Baseline & $24 / 22$ & \multicolumn{8}{|c|}{$[90 /-45 / 0 / 45]_{3 s}$} & \multicolumn{4}{|l|}{454} \\
\hline LNC & Nonconventional & $24 / 22$ & \multirow{2}{*}{\multicolumn{8}{|c|}{$[90 /-45 / 75 /-60 / 60 /-75 /-30 /-15 / 0 / 15 / 30 / 45]_{s}$}} & \multicolumn{4}{|l|}{410} \\
\hline LTP & Thick-ply & $24 / 6$ & \multicolumn{3}{|c|}{$\left[90_{3} /-45_{3} / 0_{3} / 45_{3}\right]_{s}$} & & & & & & \multicolumn{4}{|l|}{409} \\
\hline \multicolumn{15}{|c|}{ Mismatch angle value at each interface for half of the layups } \\
\hline \multicolumn{3}{|c|}{ Interface number after first ply: } & 1 & 2 & 3 & 4 & 5 & 6 & 7 & 8 & 9 & 10 & 11 & 12 \\
\hline \multirow{3}{*}{\multicolumn{2}{|c|}{ Laminate }} & LBA & $45^{\circ}$ & $45^{\circ}$ & $45^{\circ}$ & $45^{\circ}$ & $45^{\circ}$ & $45^{\circ}$ & $45^{\circ}$ & $45^{\circ}$ & $45^{\circ}$ & $45^{\circ}$ & $45^{\circ}$ & * \\
\hline & & LNC & $45^{\circ}$ & $60^{\circ}$ & $45^{\circ}$ & $60^{\circ}$ & $45^{\circ}$ & $45^{\circ}$ & $15^{\circ}$ & $15^{\circ}$ & $15^{\circ}$ & $15^{\circ}$ & $15^{\circ}$ & * \\
\hline & & LTP & $0^{\circ}$ & $0^{\circ}$ & $45^{\circ}$ & $0^{\circ}$ & $0^{\circ}$ & $45^{\circ}$ & $0^{\circ}$ & $0^{\circ}$ & $45^{\circ}$ & $0^{\circ}$ & $0^{\circ}$ & * \\
\hline
\end{tabular}

Table 3: Test matrix of the number of specimens tested; 0J: non-impacted/pristine specimens; AR: as-received or unconditioned specimens; WET: specimens conditioned at $80^{\circ} \mathrm{C} / 85 \% \mathrm{RH}$. Impactor properties-mass $=5 \mathrm{~kg}$, shape: hemispherical tub with radius $\mathrm{R}=8 \mathrm{~mm}$, material: steel of Young's modulus $\mathrm{E}=210 \mathrm{GPa}$ and Poisson ratio $\nu=0.3$.

\begin{tabular}{cccccccc}
\hline \multicolumn{2}{c}{ Impactor } & \multicolumn{5}{c}{ Laminates and conditions } \\
\hline \multirow{2}{*}{ Energy $(\mathrm{J})$} & \multirow{2}{*}{ Velocity $(\mathrm{m} / \mathrm{s})$} & \multicolumn{2}{c}{ Baseline (LBA) } & \multicolumn{2}{c}{ Nonconventional (LNC) } & \multicolumn{2}{c}{ Thick-ply (LTP) } \\
\cline { 3 - 8 } & & AR & WET & AR & WET & AR & WET \\
\hline 0 & - & 4 & 2 & 4 & 2 & 4 & 2 \\
12 & 2.191 & 3 & 2 & 3 & 2 & 3 & 2 \\
20 & 2.828 & 3 & 3 & 3 & 3 & 3 & 3 \\
30 & 3.464 & 2 & - & 3 & - & 3 & - \\
\hline
\end{tabular}

